\title{
KERANGKA KULTURAL PEMIKIRAN POLITIK DALAM LONTARA`BUGIS TERHADAP PENGUATAN BUDAYA KEWARGANEGARAAN
}

Oleh:

\author{
Fitriah Artina', Idrus Affandi' ${ }^{2}$, Muhammad Amin ${ }^{3}$ \\ ${ }^{1}$ Universitas Mataram; fitriahartina@unram.ac.id \\ ${ }^{2}$ Universitas Pendidikan Indonesia; idrusaffandi@upi.edu \\ ${ }^{3}$ Universitas Negeri Makassar; muh.amin@unm.ac.id
}

\begin{abstract}
ABSTRAK: Penelitian ini bertujuan untuk mendeskripsikan pemikiran politik lokal yang termuat dalam Lontara' bugis serta relevansinya dengan budaya kewarganegaraan. Penelitian ini menggunakan pendekatan kualitatif dengan metode penelitian kepustakaan. Data primer dalam penelitian ini ialah Lontara yakni manuskrip warisan peninggalan pengetahuan orang bugis yang dituangkan dalam bentuk tulisan, diantaranya: Latoa, Lontarak Attoriolonna to-Bone, Lontara' No. 130 tentang Rapang, Lontara Tellumpoccoe, Lontara`Koleksi YKSST Ujung Pandang (Makassar), data sekunder dalam penelitian ini ialah semua sumber kepustakaan yang memiliki relevansi dengan fokus penelitian. Pengumpulan data dilakukan dengan teknik dokumentasi dan dokumentar, dan kemudian dianalisis dengan teknik deskriptif naratif, dan eksplorasi analisis wacana kritis. Temuan penelitian menunjukkan bahwa pemikiran politik yang tertuang dalam Lontara' bugis bersifat moralistik-religius-demokratis, serta adanya komitmen penyelenggaraan kehidupan bernegara untuk kepentingan rakyat, memuat prinsip rule of law, partisipasi demokratis masyarakat, adanya jaminan hak-hak asasi manusia menurut paham kemanusiaan, serta perwujudan keadilan sosial, dampak dan relevansinya tehadap penguatan budaya kewarganegaraan bersifat integralistik secara struktural terhadap nilai-nilai Pancasila sebagai rujukan etika politik dalam penyelenggaraan kehidupan bernegara.
\end{abstract}

\section{KATA KUNCI: Pemikiran Politik, Lontara， Bugis, Budaya Kewarganegaraan}

ABSTRACT: This study aims to describe the local political thinking contained in Lontara' bugis as well as its relevance to civic culture. This study uses qualitative approach with literature research method. The primary data in this study is Lontara' which is a manuscript of heritage of bugis people's knowledge that is poured in the form of writing, including: Latoa, Lontarak Attoriolonna to-Bone, Lontara' No. 130 about Rapang, Lontara' Tellumpoccoe, Lontara' Collection YKSST Ujung Pandang (Makassar), secondary data in this study is all sources of literature that have relevance to the focus of research. Data collection is done with documentation and documentary techniques, and then analyzed with descriptive narrative techniques, and exploration of critical discourse analysis. The findings show that the political thinking contained in Lontara' bugis is moralistic-religious-democratic, as well as the commitment of the implementation of state life for the benefit of the people, contains the principles of rule of law, democratic participation of the community, the guarantee of human rights according to humanity, as well as the realization of social justice, the impact and relevance of strengthening citizenship cultural education is structurally integralistic to the values of Pancasila as a reference of political ethics in the implementation of state life.

KEYWORDS: Political thought, lontara', bugis, citizenship culture 


\section{PENDAHULUAN}

Sebuah puisi Bugis yang dikemukakan oleh Ibrahim (2003) dalam bukunya menyatakan "iya teppaja risappa, paccolli-loloenngi, aju marakkoe" (yang tak henti-hentinya dicari, yang menguncupmekarkan kayu kering), dan karya dari Richard Schechner dalam esainya tentang "The Inner and the Outer Reality", ia menuliskan bahwa "He discovers the astonishing in the banal, the unreal in the real, the new in the old, the fresh in the stale, and the archetype in the stereotype (Richard, S. 1963) yakni menemukan sesuatu yang memukau pada yang banal, yang tidak nyata pada yang nyata, yang baru, yang segar pada yang layu, yang archeptype pada yang stereotype", menjawantakan bahwa orang arif Bugis yang mencipta puisi dan Richard Schechner meyakini bahwa hasil pemikiran brilian umat manusia akan tetap memiliki nilai yang dapat dikuncupmekarkan atau disegarkan secara kreatif dan ditemukan relevansinya dengan kehidupan masa kini umat manusia. Kajian tentang pemikiran politik lokal memiliki kedudukan yang sangat penting, untuk dikaji.

Pertama, pada tingkat lokal sejarah pemikiran politik Indonesia khusunya tentang etika politik belum banyak menyoroti tentang upaya dinamika politik lokal (daerah) sehingga segmentasi pemikiran politik dari pengalaman lokal tidak banyak dihadirkan dalam wacana sejarah nasional Indonesia, disisi lain tradisi pemikiran barat sangat dominan dan menghegemoni sehingga banyak pemikir cemerlang dari bumi nusantara, kurang dikenal dalam pemikiran politik yang dipelajari di sekolah-sekolah dan Universitas.

Menurut Alfian (1971), sejarah pemikiran politik menunjukkan bahwa pemikiran politik di Indonesia selalu menganggap politik umum sebagai suatu kesatuan, bukan sebagai masyarakat yang plural dengan kepentingan yang masingmasing sebenarnya konfliktual. Hal ini menyebabkan beberapa pemikir politik gagal merumuskan politik yang baik dalam menanggapi berbagai macam masalah politik yang ada, terutama dengan masyarakatnya yang plural, pemikir-pemikir politik cenderung untuk tidak melihat fakta bahwa masyarakat terbagi dalam beberapa golongan yang memiliki kepentingan yang berbedabeda. Hal tersebut dipertegas oleh Mattulada, (2015) bahwa, "Sifat negara dapat berlain-lainan, sifat itu banyak ditentukan oleh kebijaksanaan yang menjalankan kekuasaan dalam negara itu, menurut keadaan dan kebutuhan dalam menjalankan kekuasaan, dalam menentukan sifat-sifat itu, penguasa harus senantiasa memperhatikan dan memperhitungkan banyak faktor, misalnya: Keadaan daerah-daerah, keadaan rakyat yang berhubungan erat dengan adat istiadatnya, agamanya, cara hidupnya, tingkat kecerdasannya, watak rakyatnya, begitu pula kemungkinan adanya pengaruh-pengaruh dari luar yang dibawah oleh keadaan zaman" (Mattulada, 2015).

Semua itu adalah faktor-faktor yang tidak boleh diabaikan dalam penyelenggaraan kehidupan bernegara, sehingga dalam hal ini peneliti melakukan pengkajian tentang pemikiran politik lokal orang Bugis dalam Lontara' bertujuan memberikan khazanah pemikiran politik nusantara dan memberikan preseden historis kepada negara dan para penyelenggara negara dalam memandang berbagai persoalan politik aktual baik dalam konteks pemikiran, teori, dan pendektan, sehingga penyelenggara negara dapat memahami tentang riwayat dan genealogi konseptual pemikiran politik lokal. 
Kedua, penelusuran sejarah riwayat dan genealogi kesuksesan politik Sulawesi Selatan pada masa lampau, dan pemikiran cendikiawan Bugis Sulawesi Selatan akan menambah nilai baru dalam kajian pemikiran politik lokal nusantara. Tinjauan perjalanan sejarah politik Sulawesi Selatan yang tertulis dalam Lontara' sebagai bukti penginggalan dalam bentuk manuskrip-manuskrip atau catatan-catatan tertulis hasil kesusastraan orang Bugis yang diciptakan oleh generasi masa lampau yang di tulis di atas daun lontara yang di dalamnya memuat kumpulan ucapan-ucapan, petuah-petuah dari beberapa raja dan orang-orang bijaksana (sekitar abad ke-16) mengenai berbagai hal, terutama kewajibankewajiban raja dan abdi raja terhadap negara dan rakyatnya, disamping hak dan kewajiban rakyat terhadap raja dan negaranya. berisi tentang kumpulan peraturan, undang-undang yang berlaku di dalam negeri yang berasas pada adat leluhur. berbagai macam ilmu pengetahuan tentang alam semesta, filsafat, ajaran moral dan berbagai unsur yang mengandung nilai-nilai luhur.

Dalam situasi seperti ini, pengetahuan lokal yang bersumber dari nilai budaya Bugis Sulawesi Selatan, bisa menjadi tempat berpijak yang dapat memberi sumber inspirasi baru secara mantap, dapat menjadi salah satu pendekatan dalam memberi penghargaan terhadap nilai-nilai luhur dalam kehidupan masyarakat yang kini mulai pupus, kearifan dan pengetahuan lokal yang digali dari kebudayaann akan selalu menghadirkan nuansa baru sebagai sumber inspirasi dalam menghadapi perubahan yang senantiasa dapat diterima, karena ia bersumber dari gugus "ceruk kognisi" masyarakat pendukungnya.

Ketiga, arah penguatan pendidikan kewarganegaraan dalam kajian tentang pemikiran politik lokal dikemas kedalam civic culture atau budaya kewarganegaraan merupakan salah satu sumber yang sangat bermakna bagi pengembangan civic education atau pendidikan kewarganegaraan di Indonesia. Budaya kewarganegaraan sangat erat kaitannya dengan identitas bangsa, dalam hal ini dimaksudkan sebagai identitas yang terkait budaya, kearifan lokal, serta adat istiadat yang ada di tiap-tiap daerah di Indonesia.

Menurut Winataputra (2001) mengemukakan bahwa budaya kewarganegaraan merupakan budaya yang menopang kewarganegaraan yang berisikan seperangkat ide-ide yang dapat diwujudkan secara efektif dalam representasi kebudayaan untuk tujuan pembentukan identitas warga negara", yang di dalamnya mencakup development of related external values, knowledge, and behavioral norms to meet the individual needs and characteristics (e.g. Maslow, 1970; Manz, 1986; Manz \& Sims, 1990; Mok, M. \&Pa Cheng, Y.C, 2001; Alderfer, 1972), dan berkaitan dengan "development of related values, knowledge, and behavioral norms from/to the local contexts" (Kim, 1999; McGinn, N. F. (1996).) Aspek sosiokultural dalam bangsa Indonesia telah mewujudkan integritas bangsa yang beragam dan bermacam-macam, diantaranya terdiri dari budaya-budaya etnisitas nasional, dengan demikian hal tersebut menurut peneliti dapat berubah menjadi budaya yang dapat merekatkan perbedaan sebagai salah satu alternatif untuk membangun aspek pendidikan kewarganegaraan.

Kajian tentang pemikiran politik lokal diharapkan dapat menumbuhkan kemampuan setiap wilayah untuk mendorong tumbuhnya kemandirian wilayah atau kemandirian lokal. Mengembangkan seluruh sumber daya, pengetahuan dan kemampuan, pendayaagunaan local genius dengan 
kearifan lokalnya merupakan sumber dari akumulasi pengetahuan dan pengalaman kultural dalam rangka kehidupan bersama secara nasional yang harus ditransformasikan sebagai kearifan nasional dan diarahkan untuk kepentingan pemeliharaan persatuan nasional (Riady A. Gany, 2001).

Dengan mengkaji pemikiran politik lokal, diharapkan dapat menata perilaku dan hubungan interaksi dalam kehidupan bersama dapat ditelaah, diinterpretasikan, direvitalisasikan secara kreatif sesuai spirit of time and space, yakni semangat zaman dan ruang. Untuk merelevansikan kerangka kultural pemikiran politik orang Bugis dalam Lontara' terhadap kaitannya dengan penguatan budaya kewarganegaraan (civic culture) di Indonesia, sebagai acuan, peneliti menggunakan nilai-nilai yang terkandung dalam Pancasila bahwa Pancasila sebagai representasi dari nilai politik orang Indonesia yang kemudian direlevansikan denga lima moral dasar yang diidentifikasikan oleh Heidt, (2009), (dalam Sudirman, Diakses melalui http://www.budimansudjatmiko.net/,

Sabtu, 06 Januari 2018, pukul 16.44 WIB) yakni sebagai berikut:

Tabel 1. Pancasila dan Lima Moral Dasar Menurut Definisi Heidt

\begin{tabular}{|c|c|c|c|c|}
\hline \multicolumn{2}{|c|}{ PANCASILA } & $\begin{array}{l}\text { MORAL } \\
\text { DASAR } \\
\text { HEIDT }\end{array}$ & \multirow[b]{2}{*}{\begin{tabular}{l}
$\quad$ KONSEP \\
\multicolumn{1}{c}{ DASAR } \\
Concerns about \\
physical and \\
spiritual \\
contagion, \\
including \\
virtues of \\
chastity, \\
wholesomeness \\
and control of \\
desires. \\
(Pendekatan \\
fisik dan \\
spiritual, \\
kebajikan dalam \\
kesucian, \\
mengendalikan \\
hawa nafsu)
\end{tabular}} & КЕВАЈIKАN \\
\hline $\begin{array}{l}\text { Nilai } \\
\text { Ketuhanan }\end{array}$ & $\begin{array}{l}\text { Afinitas terhadap } \\
\text { kehidupan beragama }\end{array}$ & Purity & & $\begin{array}{l}\text { - Chastity } \\
\text { (kesucian); } \\
\text { - Piety } \\
\text { (kesaleh } \\
\text { an), dan; } \\
\text { - Self } \\
\text { control } \\
\text { (kontrol } \\
\text { diri) }\end{array}$ \\
\hline $\begin{array}{l}\text { Nilai } \\
\text { Kemanusiaan }\end{array}$ & $\begin{array}{l}\text { - Soal hak asasi } \\
\text { individual : } \\
\text { - Kebebasan } \\
\text { mutlak- } \\
\text { keterpimpinan } \\
\text { mutlak } \\
\text { - Kemanusiaan } \\
\text { untuk keadilan } \\
\text { - Keadilan untuk } \\
\text { kemanusiaan }\end{array}$ & Harm & $\begin{array}{l}\text { concerns for the } \\
\text { suffering of } \\
\text { others, } \\
\text { including } \\
\text { virtues of caring } \\
\text { and compassion } \\
\text { (keprihatinan } \\
\text { atas penderitaan } \\
\text { orang lain, } \\
\text { kebajikan dalam } \\
\text { kepedulian dan } \\
\text { kasih sayang) }\end{array}$ & $\begin{aligned} \text { - Nurturance } & \text { (pengasuhan) } \\
& \text { - Care (peduli); } \\
& \text { dan } \\
- & \text { Peace } \\
& \text { (kedamaian) }\end{aligned}$ \\
\hline Nilai Persatuan & $\begin{array}{l}\text { - Soal hidup } \\
\text { bersama dalam }\end{array}$ & In Group & $\begin{array}{l}\text { Concerns } \\
\text { related to } \\
\text { obligations of }\end{array}$ & $\begin{aligned}- & \text { Loyality } \\
& \text { (loyalitas) }\end{aligned}$ \\
\hline
\end{tabular}




\begin{tabular}{|c|c|c|c|c|}
\hline & $\begin{aligned} & \text { masyarakat dan } \\
& \text { negara } \\
&- \text { Tradisionalisme- } \\
& \text { modernisme } \\
&- \text { Eksistensi } \\
& \text { individu dalam } \\
& \text { negara } \\
&- \text { Eksistensi } \\
& \text { identitas kolektif } \\
& \text { dalam negara }\end{aligned}$ & & $\begin{array}{l}\text { group } \\
\text { membership, } \\
\text { such as loyalty, } \\
\text { self sacrifice } \\
\text { and vigilance } \\
\text { against betrayal } \\
\text { (kewajiban } \\
\text { dalam } \\
\text { keanggotaan } \\
\text { suatu kelompok } \\
\text { seperti, } \\
\text { kesetiaan, } \\
\text { pengorbanan } \\
\text { diri, dan } \\
\text { kewaspadaan } \\
\text { terhadap } \\
\text { pengkhianatan) }\end{array}$ & $\begin{array}{l}\text { - Self-sacrifice } \\
\text { for group } \\
\text { (pengorbanan } \\
\text { diri untuk } \\
\text { kelompok) }\end{array}$ \\
\hline $\begin{array}{l}\text { Nilai } \\
\text { Kerjasama }\end{array}$ & $\begin{array}{l}\text { - Soal kebebasan } \\
\text { ekspresi, kerja } \\
\text { sama, dan } \\
\text { musyawarah } \\
\text { mufakat } \\
\text { - Kebebasan } \\
\text { ekspresi- } \\
\text { musyawarah/goto } \\
\text { ng royong- } \\
\text { keterpimpinan } \\
\text { mutlak }\end{array}$ & Authority & $\begin{array}{l}\text { concerns related } \\
\text { to social order } \\
\text { and the } \\
\text { obligations of } \\
\text { hierarchical } \\
\text { relationships } \\
\text { (keprihatinan } \\
\text { terkait tatanan } \\
\text { sosial dan } \\
\text { kewajiban } \\
\text { hubungan } \\
\text { hierarkis) }\end{array}$ & $\begin{array}{l}\text { - Respect } \\
\text { (menghormat) } \\
\text { - Honor } \\
\quad \text { (kehormatan) }\end{array}$ \\
\hline Nilai Keadilan & $\begin{array}{l}\text { - Soal kehidupan } \\
\text { ekonomi yang } \\
\text { berkeadilan } \\
\text { - Kesejahteraan } \\
\text { individu- } \\
\text { kesejahteraan } \\
\text { sosial }\end{array}$ & Fairness & $\begin{array}{l}\text { concerns } \\
\text { about unfair } \\
\text { treatment, } \\
\text { inequality, and } \\
\text { more abstract } \\
\text { notions of } \\
\text { justice } \\
\text { (perhatian } \\
\text { terhadap } \\
\text { perlakuan } \\
\text { yang tidak } \\
\text { adil, ketidak- } \\
\text { setaraan, dan } \\
\text { konsep } \\
\text { keadilan yang } \\
\text { abstrak) }\end{array}$ & $\begin{array}{l}\text { - Justice } \\
\text { (keadilan) } \\
\text { - Reciprocity } \\
\text { (dapat berbuat, } \\
\text { balas budi) }\end{array}$ \\
\hline
\end{tabular}

Sumber: Diadaptasi oleh Peneliti, berdasarkan konsep moral Haidt, Jonathan., Jesse Graham \& Craig, dan Pancasila)

Budaya kewarganegaraan berada dalam domain sosiokultural yang beriorentasi pada pembentukan kualitas personal-individual warga negara. Budaya kewarganegaraan bersifat psikososial yang perangkat gagasan atau set of ideas. Budaya kewarganegaraan berkenaan dengan proses adaptasi psiko sosial individu dari kaitan budaya komuniter (keluarga, suku, masyarakat lokal) dalam sebuah ikatan kewarganegaraan suatu negara atau 
kewarganegaraan. civic culture atau budaya kewarganegaraan memberi kontribusi dalam mebangun identitas

\section{METODE}

Penelitian ini menggunakan pendekatan kualitatif sebagai acuan, pola dan kerangka yang berangkat dari generalisasi empirik atas realitas-realitas sosial, politik dan budaya yang tumbuh dan berkembang, dipilihnya pendekatan kualitatif dalam penelitian ini didasarkan pada permasalahan yang akan dikaji yakni untuk mengetahui bagaimana pemikiran politik orang Bugis dalam Lontara yang membutuhkan argumentasi mendalam secara deskriptif, bukan dituangkan dalam bentuk angka atau statistik. Jenis penelitian yang digunakan yakni studi kepustakaan atau studi literatur. Sumber data penelitian melalui data literatur atau penelusuran kepustakaan.

Penelusuran data literatur dan kepustakaan dalam mengkaji pemikiran politik kehidupan bernegara peneliti menjadikan lontara' sebagai sumber primer, adapun yang dimaksud dengan lontara' ialah, “...manuscripts written on prepared leaves of the lontar palm (Borassus fla-bellifer L.) are known to be extant today...the manuscripts written in the indigenous script, both those on paper and the few on lontar leaves, are commonly known as lontaraq, a word derived from the Javanese ' lontar'" (Koolhof sirtjo, 1993). Makna lontara yang dikemukakan oleh Koohof sirtjo, merupakan manuskrip-manuskrip atau catatan-catatan tertulis yang merupakan hasil kesusastraan orang Bugis yang diciptakan oleh generasi masa lampau yang di tulis di atas daun lontara (lontar atau Borassus fla-bellifer L.) (Mattulada, 2015; Abidin Zaenal A, 1971). Menurut Macknight, C. C. Lontara' merupakan "Bugis literacy, which began with palm leaf manuscripts, has been kewarganegaraan atau ke-indonesiaan setiap warga negara, termasuk para pelaku politik dalam berbagai latar.

overwhelmingly in the form of paper manuscripts, though examples of printing, inscriptions on silver and on earthenware (Macknight, C. C. 2016), kemudian menurut Rahman Nurhayati, "orang Bugis mengenal aksara yang lebih populer disebut dengan aksara lontara', melalui aksara lontara`orang Bugis dapat mengabadikan berbagai ilmu dan kearifan masa lampau (Rahman, N, 2009). Tradisimasyarakat Bugis dalam mencatat peristiwa-peristiwa penting di atas daun lontar merupakan karya yang sangat besar artinya dalam pengumpulan data sejarah Sulawesi Selatan di Indonesia, demikian juga Koohof, Sirtjo mengemukakan bahwa, knowledge in Bugis society, the knowledge recorded in Bugis lontaraq manuscripts is of course only part of all knowledge available to the members of society (Koohof, Sirtjo. 2004). Lontara' sebagai catatan manuskrip peninggalan generasi masa lampau dalam kebudayaan dan sejarah Sulawesi Selatan memiliki kelayakan dijadikan sebagai sumber primer. Kedudukan lontara menurut Ian Caldwell, bahwa "Bugis prose texts, the nature of which (by the absence of such enquiry) appears to be singular, straightforward and unproblematic" (naskah Bugis memiliki sifat yang unik, lugas, dan tidak bermasalah atau jelas) (Ian Caldwell, `1988). Tradisi masyarakat Bugis dalam mencatat peristiwaperistiwa penting di atas daun lontar, merupakan karya yang sangat besar artinya dalam pengumpulan data sejarah Sulawesi Selatan di Indonesia, menurut J. Noorduyn, (1960) bahwa sumber historiografi tradisi dari masyarakat Bugis adalah sumber sejarah yang lebih dapat dipegang kebenarannya jika 
dibandingkan dengan sumber sumber sejarah lainnya di Indonesia. Jenis lontara`yang akan peneliti gunakan ialah lontara'yakni:

1. Lontara Latoa, secara garis besar lontara' ini memuat kumpulan ucapanucapan, petuah-petuah dari beberapa raja dan orang-orang bijaksana (sekitar abad ke-16), mengenai berbagai hal, terutama kewajiban-kewajiban raja dan abdi raja terhadap negara dan rakyatnya, disamping hak dan kewajiban rakyat terhadap raja dan negaranya. Latoa yang peniliti sajikan dan menjadi sumber primer oleh Mattulada (Disertasi 1978) dari Latoa yang termuat dalam BChr jilid II halaman 1 sampai dengan 180 yang diterbitkan oleh Matthes tahun 1872 di Amsterdam, yang disalin dari tulisan tangan (hs) pemberian Arung Pancana Collik Puji-e. Penetapan naskah Latoa, sebagai sumber data utama ini dipandang tepat, karena beberapa alasan: Latoa, merupakan lontarak orang Bugis Bone yang paling terkenal pada periode itu, dan semua tokoh yang terlibat dalam Latoa adalah toko sekitar abad ke-15, 16, dan 17.

2. Lontarak Attoriolonna to-Bone, adalah lontarak yang berisi tentang silsilah raja bone dan mengenai kerajaan bone secara turun temurun, dengan merujuk pada lontarak attoriolonna to-Bone, maka peneliti dapat menemukan bagaimana bentuk gambaran pemerintahan dan pelaksanaan kehidupan bernegara di kerajaan Bone yang disesuaikan dengan kiprah Kajao Laliddong, pertama bagaiman situasi pemerintahan dan pelaksanaan kehidupan bernegara di kerajaan Bone pada pemerintahan Raja Bone ke-4 We Banrigau, Makkalappi`e
Mallajannge ri China (1470-1510) dimana pada tahun ini Lahirnya Kajao Laliddong, kemudian Raja Bone ke-6 yakni La Ulio Bote`e Matinroe ri ltterung (1560-1578) dimana pada masa ini Kajao Laliddong diangkat menjadi penasehat kerajaan Bone; kemudian Raja Bone ke- 7 La Tenri Rawe Bongkannge, Matinroe ri Gucina (1560-1578), Raja Bone ke-8 La Ica Matinroe Addenenna (15781589); dan Raja Bone ke-9 Lapatawang Matinroe ri Butung.

3. Lontara' No. 130 tentang Rapang berisi tentang kumpulan peraturan, undang-undang yang berlaku di dalam negeri yang berasas pada adat leluhur.

4. Lontara Tellumpoccoe, isinya tentang berbagai macam ilmu pengetahuan tentang alam semesta, filsafat, ajaran moral dan berbagai unsur yang mengandung nilai-nilai luhur.

5. Lontara Koleksi YKSST Ujung Pandang (Makassar) yang banyak membicarakan tentang pemikiran dari cendikiawan Bugis Sulawesi Selatan.

Pengumpulan data menggunakan teknik dokumenter dinyatakan yang sebagai cara mengumpulkan data melalui peninggalan tertulis, terutama berupa arsip-arsip dan termasuk juga buku-buku tentang pendapat, teori, dalil atau hukumhukum, dan lain-lain yang berhubungan dengan masalah penyelidikan (Nawawi, 1995). Dalam konteks ini, peneliti akan mengumpulkan semua data yang terdokumentasikan dan memiliki relevansi dengan fokus penelitian. Data yang terkumpul, dianalisis secara mendalam dengan teknik analisis wacana kritis (critical analysis discourse), engecekan keabsahan data dalam penelitian ini dilakukan dengan tiga cara, yakni : a) kredibilitas; b) transferabilitas; c) dependabilitas. 


\section{HASIL DAN PEMBAHASAN}

Kerangka kultural pemikiran politik orang Bugis dalam Lontara dan relevansinya terhadap penguatan budaya kewarganegaraan di Indonesia dapat digambarkan sebagai bentuk manifestasi dari sebuah kearifan lokal, yang dibentuk atas dasar ide, sikap, pandangan, dan kemampuan para elit dan masyarakatnya

\begin{abstract}
dalam menentukan pembangunan peradaban masyarakat.
\end{abstract}

Ideologi sebagai sistem nilai yang terkandung dalam Pancasila, diasumsikan bahwa Pancasila merupakan representasi dari nilai politik orang Indonesia dengan lima moral dasar yang diidentifikasikan oleh Heidt kemudian direlevansikan dengan pemikiran politik orang Bugis dalam Lontara`sebagai berikut:

Tabel 2. Pancasila dan Lima Moral Dasar dalam Pemikiran Politik Orang Bugis

\begin{tabular}{|c|c|c|c|}
\hline Pancasila & Moral Dasar & $\begin{array}{c}\text { Konsep } \\
\text { Dasar }\end{array}$ & Kebajikan \\
\hline Nilai Ketuhanan & $\begin{array}{l}\text { - Afinitas terhadap } \\
\text { kehidupan } \\
\text { beragama }\end{array}$ & $\begin{array}{l}\text { Purity = } \\
\text { Dewata } \\
\text { Seuwwae } \\
\text { (Ketuhanan } \\
\text { Yang Maha } \\
\text { Esa) }\end{array}$ & $\begin{array}{l}\text { Concerns about physical and spiritual } \\
\text { contagion, including virtues of chastity, } \\
\text { wholesomeness and control of desires. } \\
\text { (Pendekatan spiritual, kebajikan dalam } \\
\text { kesucian, mengendalikan hawa nafsu): } \\
\text { - Prinsip kehatihatian (makkalitutu) } \\
\text { - Takut berkatan buruk (matau } i \\
\quad \text { makkeada maja) } \\
\text { - Takut mengambil hasil tipuan (matau } i \\
\quad \text { mala cekka) } \\
\text { - Takut berbuat aniaya (matau } i \\
\quad \text { mangkau` sala) }\end{array}$ \\
\hline Nilai Kemanusiaan & $\begin{array}{l}\text { - Soal hak asasi } \\
\text { individual } \\
\text { - Kebebasan } \\
\text { - Kemanusiaan } \\
\text { untuk keadilan } \\
\text { - Keadilan untuk } \\
\text { kemanusiaan }\end{array}$ & $\begin{array}{l}\text { Harm = } \\
\text { nyamekkininn } \\
\text { nawa } \\
\text { (Kebaikan } \\
\text { hati) }\end{array}$ & $\begin{array}{l}\text { Concerns for the suffering of others, } \\
\text { including virtues of caring and } \\
\text { compassion (keprihatinan atas penderitaan } \\
\text { orang lain, kebajikan dalam kepedulian } \\
\text { dan kasih sayang). } \\
\text { - Memelihara diri perkataan dan } \\
\quad \text { perbuatannya (madeceng kalawing ati) } \\
\text { - Martabat dan harga diri (siri`) } \\
- \text { Memiliki kesadaran (maingek) } \\
\text { - Saling menghormati (sipakatau) }\end{array}$ \\
\hline Nilai Persatuan & $\begin{array}{l}\text { - Soal hidup } \\
\text { bersama dalam } \\
\text { masyarakat dan } \\
\text { negara } \\
\text { - Eksistensi } \\
\text { individu dalam } \\
\text { negara } \\
\text { - Eksistensi } \\
\text { identitas kolektif } \\
\text { dalam negara }\end{array}$ & $\begin{array}{l}\text { In group }= \\
\text { Assedingnge } \\
\text { (Persatuan) }\end{array}$ & $\begin{array}{l}\text { Concerns related to obligations of group } \\
\text { membership, such as loyalty, self sacrifice } \\
\text { and vigilance against betrayal (kewajiban } \\
\text { dalam keanggotaan suatu kelompok } \\
\text { seperti, kesetiaan, pengorbanan diri, dan } \\
\text { kewaspadaan terhadap pengkhianatan) } \\
\text { - Seia-sekata mereka di dalam negeri } \\
\text { (massituruk-i ri lalempanuwa), } \\
\text { - Jujur mereka kepada sesamanya } \\
\text { (sialempurenngi), }\end{array}$ \\
\hline
\end{tabular}




\begin{tabular}{|c|c|c|c|}
\hline & & & $\begin{array}{l}\text { - Saling berkata benar diantara mereka } \\
\text { (siakkedatongngengnngi) } \\
\text { - Dalam duka mereka bersatu, dalam suka } \\
\text { mereka bersatu (jak nauru, deceng } \\
\text { nauruk) } \\
\text { - Tidak saling berhitung-hitung diantara } \\
\text { sesamanya (tessicirinnaianngi ri } \\
\text { salasanae), dan } \\
\text { - Saling membenarkan menurut apa } \\
\text { adanya (sipattongngenngi ri akkunae). }\end{array}$ \\
\hline Nilai Kerjasama & $\begin{array}{l}\text { - Soal kebebasan } \\
\text { ekspresi, kerja } \\
\text { sama, dan } \\
\text { musyawarah } \\
\text { mufakat } \\
\text { - Kebebasan } \\
\text { ekspresi- } \\
\text { musyawarah/goto } \\
\text { ng royong- } \\
\text { keterpimpinan }\end{array}$ & $\begin{array}{l}\text { Authority }= \\
\text { Arung } \\
\text { mangkau'e } \\
\text { sibawa to } \\
\text { mabbicara, } \\
\text { matelluann, } \\
\text { mattau seuapi } \\
\text { taue } \\
\text { lalempanua } \\
\text { (Penyelenggar } \\
\text { a negara } \\
\text { bersatu padu } \\
\text { dalam } \\
\text { penyelenggara } \\
\text { an } \\
\text { kenegaraan) }\end{array}$ & $\begin{array}{l}\text { Concerns related to social order and the } \\
\text { obligations of hierarchical relationship } \\
\text { (keprihatinan terkait tatanan sosial dan } \\
\text { kewajiban hubungan hierarkis) } \\
\text { - Megutamakan kepentingan dan } \\
\text { kesejahteraan rakyat (adecengenna } \\
\text { tanahe) } \\
\text { - Melibatkan wakil-wakil rakyat dalam } \\
\text { proses pengambilan keputusan (untuk } \\
\text { mengumumkan perang dan damai) } \\
\text { - Membuka diri dari petannga } \\
\text { (pertimbangan dan kritik) }\end{array}$ \\
\hline Nilai Keadilan & $\begin{array}{l}\text { - Soal kehidupan } \\
\text { ekonomi yang } \\
\text { berkeadilan } \\
\text { - Kesejahteraan } \\
\text { individu- } \\
\text { kesejahteraan } \\
\text { sosial }\end{array}$ & $\begin{array}{l}\text { Fairness }= \\
\text { Adecengenna } \\
\text { tanae } \\
\text { (kesejahteraan } \\
\text { negara) }\end{array}$ & $\begin{array}{l}\text { Concerns about unfair treatment, } \\
\text { inequality, and more abstract notions of } \\
\text { justice (perhatian terhadap perlakuan yang } \\
\text { tidak adil, ketidaksetaraan, dan konsep } \\
\text { keadilan) } \\
\text { - Hati nurani (ati macinnong) } \\
\text { - Sikap jiwa yang baik (madeceng kalawi } \\
\text { ati) }\end{array}$ \\
\hline
\end{tabular}

\section{Nilai Ketuhanan}

Nilai ketuhanan sebagai afinitas terhadap kehidupan beragama, konsep moral dasar pemikiran politik orang Bugis memuat adanya keyakinan pada "dewata seuwwe" (Tuhan Yang Maha Esa). Dewata Seuwe apabila ditinjau dari segi etimologi, berasal dari kata deq berarti tidak; warang berarti jasad, badan, bentuk, zat, atau kekuatan; sedangkan seuwwae berarti satu, tunggal. Jadi, jika disimpulkan dapat bermakna deq watang seuwwe ialah tidak berzat, tidak memiliki bentuk tertentu, namun tunggal adanya, artinya Tuhan itu tidak berwujud yang dapat diraba dengan indera kita seperti yang dimiliki ciptaannya, dan Dia
Tunggal, Esa, tidak ada satupun kekuatan yang dapat menyamai kekuatan yang tunggal itu. Menurut Hamid, (1985, hlm. 2), keyakinan kepada Tuhan Yang Maha Esa dalam kepercayaan nenek moyang di daearah Sulawesi Selatan sebelum agama Islam datang yakni adanya kepercayaan akan "dewata seuwe" yaitu paham akan adanya Tuhan yang kekuasaannya adalah Maha Penentu (disebut, patotoe atau Maha Pencipta; atau to palanroe).

Konsep moral dasar ini berimplikasi pada penyelenggaraan kehidupan bernegara, yakni seorang warga negara belum bisa dikatakan berkeutamaan apabila tindakannya tidak dibarengi dengan ketaqwaannya kepada 
Tuhan, semua kewenangan yang ada pada pemerintah dipandang sah apabila berlangsung dalam kesesuaian dan berdasarkan ketaqwaan, jika suatu perbuatan bertentangan dengan rasa ketaqwaan, maka perbuatan tersebut tidak mendapatkan legitimasi perintah. Ketaqwaan ini akan membawa kesadaran pejabat negara untuk mempertanggungjawabkan perintahperintah dan kebijaksanaan berhadapan dengan kehendak dewata (Tuhan).

Ketaqwaan kepada Tuhan Yang Maha Esa, mengarah pada karakteristik warga negara yang baik dalam kehidupan bernegara dalam naskah Lontara' yakni memiliki kebajikan dasar berupa kesucian atau chastity dan kesalehan atau piety sebagai kontrol diri atau self control yang berimplikasi pada tindakan warga negara yang memegang prinsip kehatihatian atau makkalitutu, warga negara yang takut berkata buruk atau matau $i$ makkeada maja, takut mengambil hasil tipuan atau matau $i$ mala cekka, serta takut berbuat aniaya atau matau i mangkau`sala.

Konsep moral dasar berupa ketaqwaan kepada Tuhan Yang Maha Esa merupakan pendekatan pembentukan spiritual dan kebajikan warga negara, mengandung isi mutlak bahwa tidak ada tempat bagi pertentangan dalam hal keTuhanan bagi sikap perbuatan anti keTuhanan, prinsip moral dasar ini mengarah pada penyatuan nilai Pancasila yakni Ketuhanan Yang Maha Esa, menggambarkan adanya sifat dan keadaan-keadaan di dalam negara harus sesuai dengan hakikat Tuhan sebagai sebab yang pertama daripada segala sesuatu atau causa prima, yang selamalamaya ada atau abadi, harus dalam arti mutlak, tidak dapat tidak, dan wajib ditaati.

Dasar moralitas dalam hubungannya dengan pelaksanaan dan penyelenggaraan negara, setiap pelaksana penyelenggaraan negara secara individual, baik dalam kapasitasnya sebagai pemimpin kelembagaan negara, sebagai wakil rakyat, sebagai tokoh atau pemimpin masyarakat/lembaga masyarakat harus mendasarkan pada dasar moralitas Ketuhanan. Sebagai seorang warga negara dan sekaligus sebagai makhluk Tuhan yang Maha Esa, medasarkan pada konsep moral Ketuhanan sesuai dengan agama yang diyakini (esensi sila I) merupakan komitmen moral yang sangat tinggi. Oleh karena itu, negara berdasar atas Ketuhanan Yang Maha Esa, merupakan pilihan kreatif dan merupakan suatu proses elektis inkorporatif, artinya pilihan negara yang berdasar atas Ketuhanan Yang Maha Esa adalah khas dan nampaknya sesuai dengan kondisi objektif bangsa Indonesia. Henry J. Schmandt, (I960), mengemukakan bahwa: "religion is the foundation of civil society", yakni masyarakat madani mejadikan agama sebagai pondasi, dalam penyelenggaraan kehidupan bernegara.

\section{Nilai Kemanusiaan}

Moral dasar sebagai nyamekkininnnawa atau kebaikan hati sebagai bentuk afiliasi keprihatinan atas penderitaan orang lain, kebajikan dalam kepedulian dan kasih sayang, yakni menempatkan dan memperlakukan manusia sesuai dengan fitrah dan kodratnya sebagai manusia. Pemerintahan yang ideal dibangun memalui sikap musiawi, yang dimaksud dengan sikap manusiawi adalah pembawaaan diri yang dilandasi oleh kasih sayang kepada sesama, bersikap manusiawi berarti kemampuan untuk melihat dunia dari sudut pandang orang lain, kasih sayang berarti, mampu berempati pada penderitaan orang lain, dan sikap mendahulukan kepentingan bangsa dan negara. Martabat dan harga diri (siri) menjadi pegangan hidup dan 
bernilai sebagai dasar dari kesusilaan umum. Manusia yang memiliki sikap jiwa yang baik atau madeceng kalawing ati akan selalu memelihara diri perkataan dan perbuatannya, manusia yang demikian memiliki kesadaran atau maingek yang kemudian kesadaran itulah tempatnya ingatan atau parenngerang dan semua perbuatan dilakukan dengan petannga atau hati nurani dengan tujuan akhir sipakatau (saling menghormati).

Malu dan harga diri merupakan kesatuan dalam diri hidup orang Bugis, dua nilai hidup ini dianggap efektif dalam menjaga harmonisasi hubungan dalam hidup bersama dalam suatu masyarakat dan negara. Moral kemanusiaan (esensi sila II) yaitu dasar moralitas kemanusiaan yang adil dan beradab, moral keadilan dalam hubungan ini mendasarkan pada core values dasar ontologi yang menurut Kaelan, (2013) bahwa, "manusia harus adil terhadap diri sendiri (jasmanirokhani), adil terhadap manusia lain, masyarakat, bangsa dan Negara (individu-makhluk sosial) dan adil terhadap Tuhan (sebagai pribadi dan sebagai makhluk Tuhan Yang Maha Esa), bahkan manusia harus adil terhadap lingkungan hidupnya.", kemudian hakikat moral kemanusiaan yang beradab, ialah manusia sebaagai makhluk yang sempurna dibandingkan dengan makhluk lainnya misalnya binatang. Letak kesempurnaan manusia harus benar-benar mendasarkan pada harkat dan martabat manusia sebagai manusia. Oleh karena itu, konsekuensi dari adanya moralitas siri dalam Lontara' yakni memuat asas-asas yang melawan adanya praktek yang bertentangan dengan prinsip moralitas manusia yang beradab, seperti: korupsi, ambisi kekuasaan, manipulasi, mafia hukum, kolusi, tindakan asusila, kezaliman, dan lain sebagainya. Dasar moralitas ini sangat penting bahkan vital dalam penyelenggaraan negara dalam konteks hidup bersama sebagai suatu kesatuan bangsa, karena bagaimanapun baiknya negara, undang-undang, serta lembaga negara bilamana penyelenggara negaranya korup, ambisi, serakah, fitnah, tidak amanah atau secara esensial tidak beradab, maka negara akan mengalami kerapuhan.

\section{Nilai Persatuan}

Konsep moral dasar assedingnge atau persatuan, merupakan hal yang sangat penting. Mattau-seuwa atau keadaan bersatu menjadi salah satu kunci kesejahteraan masyarakat yang "pasawei bua-buana ajujjajunnge, namapato laopole sangaiaserri" (merimbunkan buah-buahan serta memudahkan keberhasilan panen padi), "sialempurenngi" (jujur mereka kepada sesamanya), "siakkedatongngengnngi" (saling berkata benar diantara mereka), "jak nauru, deceng nauruk" (dalam duka mereka bersatu, dalam suka mereka bersatu), ke gunung sama mendaki, tidak saling menurunkan ke lembah (sitterreng ri-buluk-e, tessinoreng ri lompok-e), tidak saling berhitung-hitung diantara sesamanya (tessicirinnaianngi ri salasanae), dan saling membenarkan menurut apa adanya (sipattongngenngi ri akkunae).

Terpeliharnya persatuan dalam suatu negara menyebabkan apa yang disebut sebagai makbulo silappa, mallebu ittello (berbulu sebatang, berbundar telur) makna persatuan yang bundar-telur itu ialah, telur itu putih lagi bundar, intinya itulah menjadi ayam. Ayam itu mengahasilkan telur, maka yang dinamai bundar bagaikan telur, tidak ada yang mendahuluinya, tidak ada pula di belakangnya. Persatuan bulat-telur warga masyarakat adalah hasil dari perjanjian akan bersama-sama menghadapi keburukan dan kebaikan, tidak ada di atas, tidak ada di bawah, tidak di kiri, tidak di kanan, tidak di depan tidak di 
belakang, tidak di dalam, tidak di luar. Telur ayam itu mengandung inti yang akan menjadi anak. Negeri yang memelihara persatuan bulat-telur akan memperoleh kesejahteraannya. Dalam konsep ini, persatuan lahir akibat adanya kesepakatan akan kebersamaan (assamaturuseng) untuk mengahdapi dan mengatasi masalah-masalah yang dihadapi masyarakat, serta adanya rasa kesamaan dalam kehidupan bermaysrakat.

Bila bersatu bulat bagaikan telur lebih terarah pada persatuan antar warga masyarakat secara horizontal, maka persatuan bulat bagaikan beras merupakan persatuan yang bersifat vertikal, yang terbina antara raja dengan rakyatnya. Persatuan bulat bagaikan beras (mallebu berek) adalah persatuan bulat, berpalut dalam kebulatan antara raja, rakyat, dan kerajaan, yang terjadi oleh adanya perjanjian antara raja dengan rakyat.

"Tenggelam bersama dalam keburukan, muncul bersama dalam kebaikan. Tuan adalah angin, daun pepohonan si hamba, dibawa ke dalam duka dan suka, jauh maupun dekat. Apa yang akan menjadi kebesaran sang raja, akan menjadi kekuatan bagi sang hamba. Tidak saling curiga, tidak saling memandang sebagai orang lain. Si hamba tidak tengadah menginginkan kerajaan sang raja. Sang raja tidak merunduk menginginkan perhambaan sang hamba. Tidak saling merampas hak antara tuan dengan hamba. Tidak saling mendendam, tidak saling memarahi, sebab beras itu tidak punya dendam, tidak punya marah. Hanya kebulatan dan panjangnyalah yang menjadi miliknya. Maka yang disebut bundar bagaikan beras, berkepanjangan baiknya terus hingga ke anak cucunya".

Hubungan persatuan antara negeri dengan negeri, raja dengan raja, baik hubungan antar negeri-negeri di dalam kerajaan maupun hubungan antar kerajaan disebutnya sebagai persatuan bulat bagaikan bambu (mallebu bulo). Konsep ini menunjukkan hubungan dan pembinaan persatuan antara satu negeri dengan negeri lainnya di dalam kerajaan dengan mengamalkan perjanjian:

"Satu dalam duka dan satu dalam suka. Tidak saling mengadakan perbekalan. Berkata saling mempercayai, khilaf saling mengingatkan, hanyut saling menyelamatkan, jatuh saling membangkitkan, tidak saling menyembunyikan orang salah, tidak pula saling mengambil hak. Tidak saling berperkara, tidak akan mengurai yang sudah kukuh (tessiluka taro), tidak saling mengambil warisan. Tidak mencega yang melarikan barang yang sudah sepatutnya. Berumah terpencil (mabbola silellang), satu khasanah, satu harta benda. Saling hormat bagaikan tamu di rumah masingmasing. Harta benda dan hewan ternak aman di tempatnya. Tidak saling menggeser batas, tidak menggunakan kekuatan. Ke gunung sama mendaki, ke lembah sama menurun. Tidak saling menunjukkan semak belukar (buka aturan). Tidak akan saling mengambil telur, tak saling menangkap sembunyisembunyi ikan di lubuk. Sama beradatkan adatnya, sama melaksanakan peradilannya. Mereka juga mufakat, tak saling membunuh, tidak saling mengangkat senjata, tidak saling diterbangkan asap api (tidak saling membakar) atau tennarettek bessi, tennaluttureng rumpu api. Payung jadi robek, tongkat jadi aus, betis jadi penat (karena) terus menerus saling mengunjungi, demi mencapai kebaikan bersama. Demikian itulah kebulatan antara negeri dengan negeri, dan raja dengan raja, sehingga disebut bulat bagaikan buluh sebatang. Sebab buluh (bambu) itu bulat di dalam dan bulat pula di luar. Jika pecah akan rusaklah yang di dalam maupun yang di luar. Mereka menamai negerinya bersatu dalam suka 
dan duka".

Persatuan menggambarkan sebagai ikhtisar nilai persatuan Indonesia, yakni menunjukan keadaan di dalam negara sebagai sesuatu yang mutlak tidak dapat terbagi dari segala sesuatu, sebagai pertalian dan hidup kebangsaan kita, pertalian dan hidup kenegaraan merupakan alat atau jalan yang sesuai dengan kodrat manusia untuk hidup bersama, ialah bekerja sama dengan menggunakan kemampuan dan kekuatan bersama agar segala kepentingan dan kebutuhan hidup sesuai dengan martabat kemanusiaan dapat dipenuhi dengan sebaik-baiknya, pertalian dalam hidup kebangsaan dan hidup kenegaraan tidak ada tempat bagi hal-hal atau unsur-unsur yang negatif dalam arti mengurangkan, merugikan, meniadakan segala sesuatu sifat dan keadaan serta usaha penjelmaan hidup yang terkadung di dalam empat sila lainnya.

Pemikiran tentang assedingnge atau persatuan memiliki relevansi terhadap kesatuan integral bangsa dan negara Indonesia yang dipertegas dalam pokok pikiran pertama, “...Negara melindungi segenap bangsa dan seluruh tumpah darah Indonesia", yang menunjukkan bahwa pemikiran politik dalam Lontara' memuat suatu pengakuan terhadap sifat kodrat manusia sebagai makhluk individu dan makhluk sosial. Dalam pengertian demikian maka manusia pada hakikatnya merupakan makhluk yang saling tergantung, sehingga hakikat manusia itu bukanlah total individu, dan juga bukan total makhluk sosial. Relasi yang tergantung tersebut menunjukkan bahwa manusia merupakan suatu totalitas makhluk individu dan makhluk sosial, adapun penjelmaan dalam persekutan hidup bersama adalah terwujud dalam suatu bangsa yang memiliki kesatuan integralistik (Besar, 1995). Dalam pengertian ini konsep moral dasar dalam konsep assedingnge atau persatuan memberikan suatu prinsip bahwa negara adalah kesatuan integral dari unsur yang menyusunnya, negara mengatasi semua golongan bagian-bagian yang membentuk negara, negara tidak memihak pada suatu golongan betapapun golongan tersebut sebagai golongan terbesar, negara dan bangsa adalah untuk semua unsur yang membentuk kesatuan tersebut.

\section{Nilai Kerjasama}

Penetapan status, fungsi dan perang masing-masing dalam penyelenggaraan kehidupan bernegara menunjukkan sistem budaya politik yang dianut mengandung ide-ide demokrasi, yang antara lain menetapkan rakyat sebagai pemegang kedaulatan tertinggi, pemegang keteteapan yang telluka (tidak terbatalkan), secara konstitusional ditegaskan dengan ungkapan, "Luka taro arung, (batal ketetapan raja), Telluka taro adek Itidak batal ketetapan adat), Luka taro adek (batal ketetapan adat), Telluka taro anang (tidak batal ketetapan kaum), Luka taro anang (batal ketetapan kaum), Telluka taro to maega (tidak batal ketetapan rakyat)".

Sebagai konsekuensinya, di dalam penyelenggaraan aktivitas politik dan pemerintahan, raja berkewajiban mengayomi rakyat, megutamakan kepentingan dan kesejahteraan rakyat, dan melibatkan wakil-wakil rakyat dalam proses pengambilan keputusan (untuk mengumumkan perang dan damai) serta membuka diri dari petannga (pertimbangan dan kritik), rakyat dan wakil-wakil rakyat berkewajiban menaati dan melaksanakan keputusan-keputusan yang ditetapkan kerajaan, menunjukkan peran sertanya melaksanakan kewajiban serta melakukan peran dan fungsinya, sesuai statusnya masing-masing. Keterwujudan hal itu dalam kehidupan bermasyarakat, sosial dan budaya, 
memungkinkan

keharmonisan dan keseimbangan kosmos.

Terdapat dua cita-cita kefilsafatan dalam pemikiran politik orang bugis, yakni : pertama kerakyatan, yang mengandung cita-cita, bahwa negara adalah alat bagi keperluan seluruh rakyat, serta pula cita-cita demokrasi sosialekonomi, dan kedua, musyawarah atau demokrasi politik, yang kedua-duanya dijelmakan dalam asas politik negara, ialah negara berkedaulatan rakyat, sebagai cita-cita politik yang mengandung tiga unsur yakni negara untuk seluruh rakyat, demokrasi sosial ekonomi, demokrasi politik sebagai citacita politik. Intisari ini menjelma dalam dasar politik negara yakni: (1) sifat dan keadaan-keadaan di dalam negara harus sesuai dengan hakikat pada rakyat; (2) bukan negara untuk satu orang, bukan negara satu golongan, tetapi negara "semua buat semua", bahwa negara didasarkan atas rakyat, tidak pada golongan, tidak pada perseorangan, berdasarkan atas permusyawaratan, dan gotong royong, berdasarkan atas kekuasaan yang ada pada tangan rakyat (kedaulatan rakyat), bahwa negara sungguh didukung oleh rakyat, serta kepentingan serta kebahagiaan seluruh rakyat dijamin; (3) istilah kerakyatan terkandung sifat cita-cita bahwa di dalam negara dan segala sesuatu sifat dan keadaan negara adalah untuk keperluan seluruh rakyat, mengandung pengertian demokrasi yakni demokrasi politik, dan demokrasi sosial ekonomi. Demokrasi politik adalah untuk mewujudkan "persamaan dalam lapangan" dan demokrasi sosial-ekonomi adalah untuk mengadakan "persamaan dalam lapangan kemsyarakatan dan ekonomi untuk mewujudkan kesejahteraan bersama yang sebaik-baiknya, dengan demokrasi politik sebagai syaratnya, yakni "kebulatan pendapat", yaitu "mufakat" dalam “permusyawaratan/perwakilan".

\section{Nilai Keadilan}

Aadacengenna tanae atau kesejahteraan negara, sebagai konsep nilai keadilan penciptaan kesejahteraan masyarakat menjadi topik yang ditekankan secara tegas dalam pemikiran politik orang Bugis dalam kehidupan bernegara, yang dianggap menjadi ukuran kesejahteraan suatu masyarakat dan atau suatu negara ialah adanya topangan kejayaan negara dan dijalankan fungsi pengayoman oleh raja kepada rakyatnya, yang memungkinkan warga masyarakat palorong welareng pakdaung raung kaju' (memperluas jaringan kekerabatan dan merimbunkan pepohonan), warga masyarakat yang malempek sungek (memiliki harapan hidup usia yang lebih panjang, pasawe tau, pabbija olokolok (memperbanyak manusia dan mengembangbiakkan binatang ternak), pasawe bua-bua ajukkajung, mapato laopole sangiaserri (mempersubur tanaman buah-buahan dan meningkatnya hasil panen, serta adanya persatuan jiwa dan semangat seluruh rakyat. Kejayaan negara sangat dipengaruhi oleh dan berhubungan erat dengan perilaku manusia, raja, para bangsawan, pemangku adat, dan segenap warga masyarakat. Perilaku manusia seharusnya berdasar pada sikap jiwa yang baik dan bersih. Perilaku yang baik dan bersih itu bersumber dari ati macinnong (hati nurani manusia). Hati nurani adalah sumber dari sikap jiwa yang baik dan bersih, yang mendorong manusia melakukan perbuatan dan berperilaku baik, perilaku yang menimbulkan kebaikan dan kemujuran. Ati macinnong (hati nurani) yang berada di dalam manusia, mata, telinga, lidah, hidung, dan anggota-anggota tubuh lainnya hanyalah penumpang dalam diri manusia. Kemampuan fungsional anggota tubuh itu bersumber dari hati nurani. Dialah 
yang menjadikan mata melihat, menjadikan telinga mendengar, dialah yang menggerakkan lidah, dan penciuman. Oleh karena dialah, maka mata melihat tidak sembarang melihat, telinga mendengar tidak sembarang mendengar, lidah berkata-kata tidak sembarang berkata-kata, ia membaui tidak sembarang membaui, dan bergerak tidak sembarang bergerak. Manusia yang memiliki sikap jiwa yang baik (madeceng kalawi ati) akan selalu memelihara diri, perkataan dan perbuatannya. Manusia yang demikian memiliki kesadarang maingek (mengingat), kesadaran itulah tempatnya ingatan parenngereng, semua perbuatannya dilakukan dengan "peetannga" (pertimbangan hati nurani). Oleh karena itulah, maka perilaku manusia: raja, penegak hukum, bangsawan dan rakyat, harus disertai kesadaran yang memungkinkannya dapat memelihara ada tongeng (berkata dan berbuat yang benar), lempuk (kejujuran), getteng (keteguhan), sipakatau (saling menghargai dan menghormati), mappesona ri dewata seuwaE (bertaqwa kepada Tuhan Yang Maha Esa), hanya manusia yang sadar, manusia yang melakukan dialog dengan hati nurani nya yang dapat menemukan kebenaran yang sesungguhnya. Pada hati nuranilah dapat ditemukan tajanna pawinrukE` (cahaya Nya sang pencipta) sumber segala kebenaran.

Keadilan sosial berkaitan langsung dengan perilaku manusia yang memilahara diri dan kesadarannya, serta memfungsikan nuraninya. Perilaku yang menempatkan segala sesuatu pada tempatnya secara proporsional, dapat memberikan harapan hidup yang panjang, memanjangkan usia (lamperi sungek) adalah dengan mengembangkan perilaku yang memelihara kejujuran (lempu'e), dengan membuktikan perbuatan yang: memaafkan orang yang bersalah padanya, tidak culas bila diberi kepercayaan, tidak serakah terhadap yang bukan hak nya, dan tidak mencari kebaikan bila hanya dia yang menikmatinya. Sedangkan untuk mengembangkan jumlah manusia dan membiakkan ternak (pasawe tau, pabbija olokolok) diperlukan pemeliharaan perilaku yang menunjukkan nilai keteguhan dan ketegasan dalam prinsip yang benar (getteng), dengan bukti perbuatan: tidak mengingkari janji, tidak mengkhianati ikrar (perjanjian) antar kerajaan, tidak merusak ketetapan terdahulu, tidak mengubah permufakatan, dan menyelesaikan dengan tuntas bila mengadili perkara. Ditunjukkannya delapan jenis perilaku yang menjadi bukti sikap getteng (keteguhan); tidak melebihlebihkan perkataan, tidak mengurangi perkataan, melaksanakan tugas dengan baik, mengucapkan perkataan yang benar, melakukan perbuatan yang benar, melakukan perbuatan yang bermanfaat pada manusia, melakukan perbuatan dan mengucapkan kata-kata yang patut, memberikan bantuan kepada orang lain sesuai kewajaran, dan merendahkan diri sepatutnya.

Kesejahteraan masyarakat ditandai pula oleh melimpahnya bahan makanan, baik buah-buahan maupun meningkatnya hasil panen, terutama padipadian. Hal itu terjadi bila hakim berpantang, bila raja memerintah bersikap baik terhadap seisi rumahnya, bila bersatu padu rakyatnya di dalam negeri. Kebaikan di dalam istana raja ditandai oleh perilaku raja yang jujur, teguh, dan tegas, berpegang kepada kebenaran, raja tidak menjamah isi rumahnya, maksudnya raja tidak melakukan perbuatan tidak senonoh menurut aturan adat kepada dayangdayangnya, dan tidak masuk ke istana raja barang hasil perbuatan sewenangwenang.

Perilaku manusia, baik raja, pabbicara (penegak hukum), para 
bangsawan, dan rakyat secara keseluruhan sangat berkaitan dengan pencapaian kesejahteraan masyarakat. oleh karena eratnya hubungan kesejahteraan masyarakat dengan perilaku mansuia, maka ditegaskannya lima sifat yang akan mencegah timbulnya penyesalan, yaitu berpikir-panjang sebelum melakukan sesuatu perbuatan dan/atau mengucapkan perkataan; menggunakan pertimbangan matang, menggunakan akal dan kemampuan menentukan pilihan, selalu memelihara martabat dan harga diri, dan memiliki sikap yang selalu berhati-hati. Perilaku yang benar serta kata-kata yang benar, tempatnya pada orang yang berpikiran panjang, perbuatan yang patut dan tepat, tempatnya pada orang yang menggunakan pertimbangan matang, perkataan yang baik dan tidak serampangan, tempatnya pada orang pintar. Sedangkan perilaku jelek dan perkataan buruk tempatnya pada orang yang sesat, dan perilaku salah serta perkataan salah, tempatnya pada orang dungu. Maka dari itu, ada tiga kesimpulan yang dapat kita ambil yakni, (1) dalam hidup bersama harus ada keadilan sosial, karena hanya dengan demikian kepentingan dan kebutuhan hidup setiap warga hidup bersama dipenuhi samasama atau dengan perkataan lain, keadilan sosial adalah bawaan kodrat dari adanya kepentingan dan kebutuhan hidup mutlak, jadi inilah yang menjadi pangkal dasar dari keadilan sosial; (2) sebagai bawaan kodrat, maka ia tertanam di dalam hati sanubari manusia; (3) keadilan sosial adalah bawaan dari sifat kodrat monodualis manusia atau kesatuan kodrat perseorangan dan sifat makhluk sosial.

\section{PENUTUP}

Pemikiran politik yang tertuang dalam Lontara bugis bersifat moralistikreligius-demokratis, serta adanya komitmen penyelenggaraan kehidupan bernegara untuk kepentingan rakyat, memuat prinsip rule of law, partisipasi demokratis masyarakat, adanya jaminan hak-hak asasi manusia menurut paham kemanusiaan, serta perwujudan keadilan sosial, kemudian dampak dan relevansinya tehadap penguatan Pendidikan budaya kewarganegaraan bersifat integralistik secara struktural terhadap nilai-nilai Pancasila sebagai rujukan etika politik dalam penyelenggaraan kehidupan bernegara. Bagi bangsa Indonesia, atribut-atribut itu dapat menjadi rujukan operasional penyelenggaraan PKn, yang diletakkan dalam bingkai ideologi Pancasila dan konstitusi negara UUD 1945. Perilaku politik seperti Dewan Perwakila Rakyat (DPR), pejabat negara, dan organisasi non-pemerintah secara subtansi dan praksis menggambarkan karakter $\mathrm{Ke}$ Indonesiaan, bukan karakter komunitarian suku, agama, golongan, dan partai politik, kualtis pribadi warga negara yang diperlukan ialah terwujudkan kualitas pribadi yang ditandai oleh keimanan dan ketaqwaan kepada Tuhan Yang Maha Esa, penghormatan terhadap hak asasi manusia, perwujudan negara hukum, partisipasi warga negara yang luas dalam pengambilan kebijakan publik dalam berbagai tingkatan, dan pelaksanaan paradigma baru pendidikan kewarganegaraan untuk mengembangkan warga negara Inodenesia yang cerdas dan baik. Salah satu unsur dari budaya kewarganegaraan adalah civic virtue atau kebajikan atau akhlak kewarganegaraan yang mencakup keterlibatan aktif warganegara, hubungan kesejajaran/egaliter, saling percaya dan toleran, kehidupan yang kooperatif, solidaritas, dan semangat kemasyarakatan. 


\section{DAFTAR PUSTAKA}

Alderfer, C. P,.(1972). Existence, relatedness, and growth: Human needs in organizational settings. New York: Free Pres.

Besar, Abdul Kadir. (1995). Cita Negara Persatuan. Jakarta: BP-7 Pusat.

Ibrahim, A. (2003). Sulesana Kumpulan Esai tentang Demokrasi dan Kearifan Lokal. Makassar: Lembaga Penerbitan Universitas Hasanuddin (Lephas).

Kaelan. (2013). Negara Kebangsaan Pancasila: Kultural, Historis, Filosofis, Yuridis, dan Aktualisasinya. Yogyakarta: Penerbit Paradigma.

Kim, Y. H. (1999). Recently changes and developments in Korean school education. In Townsend, T., \& Cheng, Y. C. (eds). Educational change and development in the Asia-Pacific region: Challenges for the future. The Netherlands: Swets and Zeitlinger.

Koolhof, Sirtjo. (2004). The Sleeping Giant. Dynamics of a Bugis Epic (South Sulawesi, Indonesia). In: J. Jansen and H. M. J. Maier (eds) Epic Adventures. Heroic Narrative in The Oral Performance Traditions of Four Continents. Münster: Lit Verlag.

Noorduyn, J,. (1960). Origin of South Celebes, Historical Writing. New York: Cornell University Press.

Mattulada, H. (2015). Latoa Antropologi Politik Orang Bugis. Yogyakarta: Ombak.

Maslow, A. (1970). Motivation and personality (2nd ed.). New York: Harper \& Row.

Manz, C. C., and Sims, H. P., Jr,. (1990). Super Leadership. New York: Berkeley.
Nawawi, H. 1995. Metode Penelitian Bidang Sosial. Yogyakarta: Gajah Mada. University Press.

Riady, A,. (2007). Kajao Laliddong Pemikir Besar dari Tanah Bugis. Makassar: La Macca Press.

Rahman, Nurhayati,. (2009). Kearifan Lingkungan Hidup Manusia Bugis Berdasarkan Naskah Meong Mpaloe. Makassar: La Galigo Press.

Schmandt, Henry J,. (1960). A History of Political Philosophy. Milwaukee: Bruce.

Winataputra, Udin. S. (2001). Materi dan Pembelajaran IPS SD. Jakarta: Universitas Terbuka.

Alfian. (1971). Indonesia Political Thinking: a Review. Jurnal Indonesia. Vol. 11: 193-200.

Koolhof, Sirtjo and Roger Tol. (1993). The Delight of The Dutch Compagnie. On the Toloqna

Musuq Boné by Daéng ri Aja. Jambatan. Tijdschrift voor de geschiedenis van Indonesië. Vol.11(3):99108.

Manz, C. Charles. (1986). SelfLeadership: Toward an Expanded Theory of SelfInfluence Processes in Organizations. The Academy of Management Review. Vol. 11 (3): 585-600.

Mok, M. \& Cheng, Y.C. (2001). A Theory of Self Learning in a Human and Technological Environment: Implications for Education Reforms. International Journal of Education Management. Vol. 15(4): 172-186.

McGinn, N. F. (1996). Education, Democratization, and Globalization: A Challenge for Comparative Education. 
Comparative Education Review, 40(4), 341-357.

Macknight, Campbell. 2016b. The Media of Bugis Literacy. A Coda to Pelras. International Journal of Asia Pacific Studies. Vol. 12 (1): 53-72.

Richard, Schechner (1963). The Inner and The Outer Reality. The Tulane Drama Review. Vol. 7 (3): 187-217.

Abidin, Zainal. A. (1971). Notes on The Lontara' as Historical Sources. Indonesia. 2th Seminar National History. Yogyakarta: Agustus 1970.

Caldwell, I. A. (1988). South Sulawesi AD 1300-1600: Ten Bugis Texts. Disertasi. Australia: Australian National University.

Budiman Sudjatmiko. (2001). Nilai politik: Berakhirnya "The End of Ideology?. Diakses melalui http://www.budimansudjatmiko.net/, Sabtu, 06 Januari 2018, pukul 16.44 WIB. 